\title{
Equatoripal
}

\section{O mercado do comércio justo}

\author{
Antonio Daniel Alves Carvalho \\ Doutorando em Sociologia \\ Universidade Federal de Sergipe \\ paradanielalves@gmail.com
}

\section{RESUMO}

O texto articula o pensamento social sobre a categoria mercado e aplica o que é denominado aqui de conceito sociológico de mercado ao modelo de mercado do comércio justo. O comércio justo é um modelo alternativo ao mercado convencional e traz inúmeros elementos para o questionamento do atual modelo de mercado internacional. Assim, o objetivo do artigo é analisar o mercado como um conceito sociológico e interpretar o modelo de mercado do comércio justo de acordo com as concepções balizadas pelo aporte teórico de Weber, Polanyi e Granovetter, autores que contribuíram com a sociologia econômica trazendo ao debate o mercado como um espaço de ação social. Metodologicamente utiliza-se a pesquisa exploratória através de uma revisão bibliográfica. Aqui é considerado o mercado como fruto das relações sociais e é evidenciado que o mercado do comércio justo faz uso das relações entre os atores sociais para questionar o modelo de mercado internacional convencional, apresentando outro modelo de comercialização que considera questões sociais além das econômicas.

Palavras-chave: Mercado; Sociologia Econômica; Comércio Justo.

\section{Introdução}

O mercado é o espaço de troca onde cada agente busca suprir as suas necessidades. Principia-se dessa afirmação para realizar a análise do que seria o mercado. Nesse sentido, o artigo pretende entende-lo como um conceito social, já que ele pode figurar entre as criações da sociedade humana.

O mercado do comércio justo é um modelo alternativo ao comércio convencional, pois apresenta características que o distanciam das trocas visando apenas ao lucro financeiro. O modelo do comércio justo reduz a distância entre consumidor e produtor, reduzindo os atravessadores, além de trazer 
elementos de valorização social ao mercado, como preço justo, sustentabilidade, inclusão do produtor na economia global, entre outras. Essas ações o tornam crítico direto ao modelo convencional do mercado internacional.

Outros modelos de economia têm adicionado valores não econômicos ao mercado. Entre eles temos o Comércio Justo, aqui analisado, que, como prática, traz mudanças tais como um valor diferente do produto para consumo - pois agora o consumidor paga pelo produto e por um "valor" social destinado a sociedade dos produtores -, a redução da distância entre produtor-consumidor, a busca por práticas sustentáveis e por dar ênfase não apenas ao produto, mas também ao sujeito e à sociedade que o produz.

O mercado do comércio justo apresenta um paradoxo: como um mercado pode ser justo? As economias clássicas e neoclássicas defendem um modelo econômico no qual os indivíduos agem em busca da satisfação de suas necessidades considerando o menor custo e maior lucro, ou seja, realizando uma escolha racional. Já o comércio justo percebe que ação do indivíduo está ligada também a ideias de justiça, equidade, preservação do ambiente, respeito das diferenças de gênero e raça, dignidade do trabalhador e etc., quer dizer, considera outros valores que não apenas os economicistas. Essa questão evidencia uma das especificidades do comércio justo, que necessita ser interpretada pela sociologia econômica, pois sua prática se distancia do mainstream econômico e agrega outros valores as trocas comerciais.

Nesse contexto, o artigo ${ }^{1}$ busca realizar uma análise do que seria o mercado como um conceito sociológico, ou seja, compreender o mercado como uma variável dependente da sociedade. A análise será realizada por meio das reflexões de Weber, Polanyi e Granovetter que buscaram compreender o fenômeno como uma ação social.

\section{Mercado, um conceito sociológico}

O mercado é uma categoria que tem sido, em certa medida, abordada pelos economistas de forma natural como um espaço de trocas. Raramente encontramos na literatura uma preocupação com a conceituação do fenômeno. Talvez essa tarefa pertença aos sociólogos que encontraram no mercado uma forma de interação e, assim, não têm como escapar à identificação 
de seus atributos distintivos. Nessa ótica, Weber presta um serviço notável pela riqueza analítica, atento às variáveis do fenômeno. $\mathrm{O}$ autor alemão, que é considerado um dos pais fundadores da sociologia, viveu entre 1864 e 1920 e o seu pensamento girou em torno da ação social e da racionalidade dos atores sociais, considerados na sua obra como responsáveis pelas mudanças e execução das ações sociais. O texto weberiano caracteriza o mercado como uma relação comunitária na qual a ação social tem base no sentimento subjetivo e racional dos participantes de pertencerem ao mesmo grupo, ou seja, constituírem um todo, de uma forma não associativa (WEBER, 1991).

O mercado funciona pela união de interesses racionalmente motivados. A troca se caracteriza como uma relação associativa que se esgota no interesse de cada uma das partes. No entanto, o mercado resulta de uma comunidade constituída das trocas. O que torna a ação econômica uma condição objetivamente compartilhada com outros de seus pares a partir de certos atributos e circunstâncias socialmente identificáveis.

Diante disso, na compreensão weberiana, o mercado é a forma de socialização por excelência que é simultaneamente interessada e solidária. Existe nele a possibilidade do reconhecimento de que todos podem legitimamente perseguir apenas o seu próprio interesse individual sem se preocupar com o outro, mas não menos importante na configuração do mercado é o reconhecimento universal de que cada um é portador de direitos que não podem ser violados, caso contrário, não existiria troca e sim roubo. Weber (1991) afirmou que o mercado é uma forma de socialização possível entre estranhos. Nessa ideia transparece a ambiguidade do fenômeno: emancipatório por autorizar a perseguição de fins pessoais e opressivo por viabilizar, rotinizar e legitimar a indiferença recíproca. Com essa premissa, talvez possamos deduzir que uma sociedade crescentemente complexa, que não se fundamenta sobre laços pessoais estabelecidos entre seus membros, é cada vez mais mercantil. Contribuindo para uma expansão de relações pacíficas, porém mais impessoais (WEBER, 1991).

Nessa ótica, a emergência de formas complexas de sociedade ao longo dos últimos séculos acaba por conferir ao modelo economicista do fenômeno uma centralidade inusitada em formações sociais, por sua característica ímpar, qual seja a contínua impessoalidade das formas de socialização produzidas ao 
longo do processo conhecido por modernização. Weber evidencia que, em virtude da impessoalidade, é possível a socialização entre estranhos, o que é corriqueiro nas sociedades complexas. O contato entre pessoas estranhas é frequente e atribui ao mercado o papel de liga social. No entanto, a economia neoclássica atribui a ele uma autonomia e independência de todas as relações sociais e de poder, tornando-o não influenciável por ações e relações sociais. A economia percebe o mercado como espaço para ações racionais e utilitaristas. É esse modelo ao qual se contrapõe a proposta de Karl Polanyi (2011).

O pensamento de Polanyi (2011), estabelecido na obra a A grande transformação, de 1944, traz as suas compreensões dos mercados. O autor é considerado substantivista por definir a economia como um processo instituído de interação entre o homem, ambiente natural e social que o rodeia e resulta em contínua oferta de meios para satisfazer as necessidades humanas (MACHADO, 2014). A regulação da vida social pelo modelo economicista depende da existência de instituições e valores específicos, portanto, não pode ser considerada natural. Esse pensamento se opõe à relativa naturalização da operação do fenômeno, marca dos autores liberais da economia. Para Polanyi (2011), nenhuma economia havia sido controlada por mercados até a modernidade.

A sociedade moderna deu ao mercado oportunidade de preencher as necessidades funcionais de fartura relativamente rápida, atomizada e descentralizada de alocação de recursos e informações. Fernand Braudel (1987) verifica que a capacidade reguladora do mercado é apenas parcial, não sendo possível explicar toda a vida social. Essa interpretação funcional não pode explicar o surgimento do mercado, mas sugere uma explicação para a sua disseminação, a partir de mecanismos de filtro e de mimese social. $O$ autor constata assim a existência de um pré-mercado e de um mercado (POLANYI, 2011) como mecanismo de estratificação social competitiva. Observamos, que mais do que uma relação causal, a exclusão mútua entre mercado e pré-mercado é matéria de definição e contra definição. Com o pré-mercado não existe liberdade/autonomia para competir e maximizar o lucro, opondo-se ao mercado moderno.

Neste sentido, somente em sociedades altamente complexas os contatos pessoais com estranhos tornam-se suficientemente frequentes para permitir ao mercado sobrepor-se aos modos formais de interação. Es- 
boçamos dois modelos sociais opostos, portadores de muitas de nossas práticas e ideais. Um submisso, o pré-mercado e um livre/autônomo, o mercado moderno. Podemos afirmar que jamais existirá sociedade alguma que reproduza fielmente qualquer desses extremos, sendo essa definição um tipo ideal para sintetizar a ideia de mercado e pré-mercado.

Nessa lógica, de uma sociedade cada vez mais complexa e de crescente competição interna, o mercado é na sua origem a forma de socialização possível entre estranhos, distinguindo a moderna sociedade complexa das demais. Nela estamos condenados a reservar ao mercado um papel relevante na configuração de um mundo. Mesmo que admitamos que ele nem sempre tenha exercido esse papel (POLANYI, 2011) e reconhecendo que ele não é o único princípio organizador da sociedade e que outras formas de socialização e introjeção de valores estarão presentes.

Para Polanyi (2011), o século XIX foi marcado por interpretações simplistas do sistema social e, além disso, releituras de autores importantes, como Adam Smith, sem propriedade porque situadas em tempos diferentes do original, acabaram por reduzir a divisão do trabalho que, segundo ele, sempre fora orientada segundo fatores diversos. Além disso, Polanyi (2011) reconhece a existência do mercado, da troca, o que, por si só, pode parecer redundante, antigo, mas para ele a orientação da sociedade pelo fenômeno social, isso sim, é tão nocivo quanto recente.

Em decorrência disto, o mercado e a troca ocorreriam de forma garantir um processo natural das relações sociais que é o de redistribuição. Existe a necessidade de se estabelecer, para o funcionamento da sociedade, a reciprocidade, a troca e a redistribuição, de forma que se possa observar um movimento contínuo de ajustamentos. E, neste caso, a divisão do trabalho fica assegurada. Isso não quer dizer que sempre exista um equilíbrio entre essas relações, o que possibilita a existência de relações simbióticas entre os membros de uma comunidade; mas, de alguma forma, as relações sociais absorvem as relações econômicas puras.

O que Karl Polanyi (2011) ressalta é a existência de um movimento duplo formado, de um lado, por um princípio liberal econômico que insiste na autorregulação do mercado; e de outro, pela proteção social que aponta à conservação dos homens e de sua natureza, como também, de sua capa- 
cidade produtiva. A noção de movimento duplo parece insinuar uma medida de adaptação, que fez com que, por exemplo, gerações sucessivas de trabalhadores viessem a aceitar a disciplina de trabalho nas fábricas e os empregadores apreendessem o valor do trabalhador como um recurso.

A imersão do mercado na vida social tem transformado a sociedade e modificado os valores que são inerentes ao sistema econômico e aos processos da modernidade. Polanyi (2011) reconhece as multiplicidades de mecanismos que formam a sociedade moderna, não dando ao mercado o papel central na ação social. Com essas premissas, percebemos que o mercado (o fenômeno) é um conjunto de ações que modificaram as interações sociais, aumentando a capacidade social do indivíduo e tem também a capacidade de autorregulação distanciada das relações sociais. No entanto, é relativamente responsável pelas mudanças sociais.

Com base no pensamento de Polanyi (2011), o sociólogo americano Mark Granovetter, nos anos de 1980, busca interpretar os fenômenos econômicos naquilo que os torna fenômeno social, ou seja, nas relações sociais, nas estruturas e instituições sociais. Isso se dá através da análise da ação econômica dos indivíduos e suas redes de relações sociais. Granovetter compreende a ação econômica com inspiração em Weber e diz que a definição sociológica da ação econômica feita por ele seria mais ampla do que a dos economistas, por englobar aspectos que eles desprezaram, como o caráter afetivo e tradição da ação; elementos destacados nas tipologias da ação social weberiana que, a princípio, pressupõe a interação entre indivíduos, diferenciando-se das visões atomísticas do ator produzidas pelos economistas (SMELSER e SWEDBERG, 2005).

Em Granovetter (2007) a ação econômica não é analisada de forma isolada, mas em seus contextos sociais. Podendo ser entendida como a rede de relações sociais, equivalente a uma forma de interação social que põe indivíduos em contato; essas interações podem ser transações realizadas em um mercado, podem ser trocas de serviços entre indivíduos de um mesmo bairro ou podem ser a presença dos indivíduos nos conselhos de administração de um conjunto de empresas. São características fundamentais do mercado, de acordo com a nova sociologia econômica, os vínculos concretos com o social que se desdobram na imersão da ação econômica em redes sociais tecidas pelos indivíduos 
e motivados por múltiplas razões. O autor de Ação econômica e estrutura social: o problema da imersão busca discutir e ampliar a noção de enraizamento de Polanyi (2011), reinterpretado a partir da noção de redes sociais, considerando que a posição do indivíduo nessas redes deveria ser o ponto de partida para a análise da vida econômica (SWEDBERG apud ABRAMOVAY, 2004, p. 36).

Granovetter localiza sua argumentação sobre a questão da imersão (embeddedness) ou de como nas sociedades modernas a ação econômica está imersa nas relações sociais (como os comportamentos e as instituições são afetados pelas relações sociais) dentro de uma tradição mais ampla da teoria social.

\section{O comércio justo como modelo de mercado}

As mudanças de interpretações do mercado na sociedade moderna são base para pensar alternativas de torná-lo mais humanizado, como observamos no movimento comércio justo, que busca uma alternativa menos utilitarista à ação econômica. O movimento do comércio justo surgiu em meados do século XX como uma iniciativa inovadora para abordar a marginalização e o subdesenvolvimento dos pequenos produtores agrícolas do Sul, desafiando o intercâmbio desigual entre o Norte e Sul², especialmente em relação aos commodities agrícolas. Esse movimento social é organizado internacionalmente por meio de redes compostas por produtores, organizações, comerciantes e consumidores que procuram um padrão mais equitativo do comércio, através do desenvolvimento sustentável e o acesso dos produtores desfavorecidos do Sul para comercializar produtos no mercado do Norte e contribuir para melhorar a sua qualidade de vida.

Criado com o objetivo de promover o consumo de produtos que considerem o pagamento de um preço justo aos produtores, a promoção de valores sociais e o respeito ao ambiente; esta variante do movimento de comércio alternativo se apresentou aos produtores do Sul, habitualmente marginalizados por causa de seu pequeno tamanho e da capacidade limitada de participação e negociação no comércio internacional. A possibilidade de evitar todo o peso das forças de mercado, por meio de redes de comercialização, encurtou a distância entre o produtor e o consumidor, procurando um comércio mais justo e equitativo.

Há muitas definições de termos que se relacionam com o comércio justo, 
quais sejam: justas, equitativas, alternativo, solidariedade. Todos têm em comum a busca de igualdade de oportunidades, o desenvolvimento econômico, pagamento justo por produto ou serviço, respeito ao meio ambiente, igualdade de gênero, repúdio ao trabalho infantil e o benefício de todo o seu público: produtores, organizações e consumidores. Comércio justo é uma parceria comercial, baseada em diálogo, transparência e respeito, que busca maior equidade no comércio internacional. Ele contribui para o desenvolvimento sustentável através de melhores condições de troca e a garantia dos direitos para produtores e trabalhadores marginalizados - principalmente do Sul (SCHNEIDER, 2012).

Neste sentido, o comércio justo é impulsionado por pequenos agricultores em áreas empobrecidas do Sul que encontram uma maneira de viver com dignidade, ao mesmo tempo que os consumidores podem obter produtos de qualidade, tanto ambiental como social. A ligação entre o produtor e consumidor passa a ter um intermediador e não um atravessador, existente no comércio tradicional. Esse modelo é um mecanismo no qual a mudança na relação comercial se faz através de uma relação direta, produtor-consumidor, diferenciando um produto, pois ele passa a ter características sociais diferentes dos produtos do comércio convencional, em outras palavras ele passa a ter outros elementos. O movimento não funciona como mecanismo de caridade, mas de solidariedade com apoio ao desenvolvimento de potencialidades da comunidade.

Esse modelo de comércio rejeita os paradigmas mecânicos da teoria da economia neoclássica. A ênfase nesse modelo é a preocupação com o custo social, na qual é considerada a sua influência contra o subdesenvolvimento, e em prol da saúde, da educação e da economia, ou seja, o comércio justo se preocupa em incluir o preço social em suas mercadorias favorecendo a melhoria de vida dos trabalhadores. Todas as qualificações e [re]significações trazidas pelo comércio justo, em certa medida, são previstas no arcabouço jurídico de alguns países e tornam-se relevantes por reafirmar medidas que contrariam a ideia de mercado desregrado. No entanto, a modernidade, em seus processos de desencaixe e reencaixe (GIDDENS, 1991), consegue deslocar o que antes era tido como tradicional e colocá-lo em uma nova posição, como a coisificação do homem e a venda de seu trabalho. Pode-se de forma tímida observar que o comércio justo trabalha com essas 
categorias, quando propõe uma relação mais justa, e aqui nos remetemos a Aristóteles [335 a.C. a 323 a.C] (1996) quando afirma que a justiça é aproximação com a igualdade, ou seja, tratar os iguais como iguais e os diferentes como diferentes, questionando o termo justo que nos leva ao substantivo justiça, definido como:

A justiça é a forma perfeita de excelência moral porque ela é a prática efetiva da excelência moral perfeita. Ela é perfeita porque as pessoas que possuem o sentimento de justiça podem praticá-la não somente a si mesmas como também em relação ao próximo. (ARISTÓTELES, 1996, p. 195).

A relação de justiça com comércio é paradoxal, ora tem-se um modelo autorregulado em que os agentes tendem a exercer os seus interesses sem pensar no outro, facilitando as relações com os estranhos, ora a ideia de igualdade é a absorvida pelo mercado como liberdade e possibilidade de ações neste espaço. O comércio justo busca levar essa possibilidade de justiça e liberdade aos produtores que são injustiçados no contexto econômico, descortinando outra percepção sobre a justiça que é calculada pelo seu oposto, a injustiça.

Retornando aos processos de desencaixe e encaixe, podemos perceber a posição do produtor marginalizado do Sul que é excluído das relações comerciais internacionais por inúmeros fatores, colocando esse sujeito à margem do sistema econômico. A relocação desse mesmo produtor num modelo econômico global traz a possibilidade de maior negociação e desenvolvimento da qualidade de vida do sujeito e da comunidade.

Para Giddens (1991), os processos que configuram a modernidade são percebidos quando o produtor marginalizado e desfavorecido é colocado como agente de negociação de caráter igualitário aos demais agentes no mercado, saindo da posição de desfavorecido e explorado e passando a ser um agente de negociação em igualdade, como a teoria econômica atribui aos agentes imersos no mercado. Retirar esse indivíduo de um sistema de significações e possibilidades e inseri-lo em outro sistema, transforma o sujeito e seu modelo social, evidenciando que o reencaixe desse sujeito seja necessário para a disseminação da modernidade e da economia, pois o novo encaixe o condiciona como agente da modernidade da economia de mercado.

O comércio justo funciona como modelo de certificação internacional visando à inclusão dos produtores marginalizados do Sul no comércio inter- 
nacional. As principais certificadoras desse mercado são a Fairtrade Labelling Organizations International (FLO), no mercado agrícola de varejo, World Fair Trade Organization (WFTO), com a produção agrícola certificação de produtos artesanais e FAIRTRADE USA, que certifica diversos produtos agrícolas e produtos com matéria-prima de origem do mercado justo nos EUA e Canadá.

Toda a rede de produção e distribuição é certificada para reduzir os custos dos produtos e evitar a exploração por parte de importadores internacionais. Assim, o comércio justo busca a redução da distância entre produtores e consumidores, possibilitando maior rendimento ao produtor. Além dessa facilitação é ainda dado ao produtor um prêmio social que deve ser revestido em benefícios para a comunidade envolvida no comércio justo.

As transações seguem em maior parte o seguinte padrão: o produto se adequa às normas para ser certificado. Isso garante a venda de sua produção por um preço mínimo estabelecido pela certificadora, que ainda possibilita o pagamento antecipado de parte da produção; depois de produzido o comprador se responsabiliza pelas tributações e transporte do produto, as vendas são realizadas em world shops que são lojas especializadas em vendas de produtos comércio justo e no varejo em supermercados.

O comércio justo tem alguns princípios norteadores de suas ações. São eles: a transparência e corresponsabilidade nas relações comerciais; desenvolver a independência do produtor; preço justo; igualdade de gênero; respeito às leis trabalhistas nacionais e da Organização Internacional do Trabalho (OIT) e formas sustentáveis de produção. Esses princípios são buscados para garantir uma melhor qualidade de vida para o produtor e a inclusão dele no mercado internacional e, principalmente, dar condições de vida dignas para todos.

Aqui, temos a atuação de grupos que redirecionaram suas práticas produtivas ao investirem na produção e comercialização de produtos de acordo com o comércio justo, estes que, por princípio, estariam fundamentados na ideia de que o processo produtivo deve estar orientado por uma relação sinergética entre homem e natureza, minimizando o máximo possível seu impacto sobre esta última. Nesse contexto, foram abertas muitas possibilidades de produção e de comercialização de produtos alimentares. 
Os modelos de economias alternativas que são desenvolvidas, em foco aqui o comércio justo, apontam para a transformação do mercado como uma ação social, negando o seu caráter, em muitos casos exclusivista, autônomo e desvinculado das relações sociais. Considerando que as atividades humanas são confeccionadas, significadas e executadas por sujeitos em interação é possível então pensar um conceito sociológico de mercado como uma atividade social.

\section{Considerações finais}

O comércio justo é um conceito confeccionado através da experiência de inúmeros sujeitos que buscaram garantir a inclusão de grupos marginalizados ao comércio global, tendo a intenção de garantir uma melhoria na qualidade de vida das comunidades que, em muitos casos, sofriam privações de recursos básicos para se constituírem uma comunidade. Esse modelo se enquadra no que é conhecido como ATO (Alternative Trading Organization) ${ }^{3}$, organizações de econômicas que buscam relativizar o mercado mainstream e tentam inserir outros modelos de ações no modelo economicista vigente.

É necessário, ainda, destacar as perspectivas teóricas dos autores que contribuíram para a concepção do mercado como um espaço de caráter relacional. Weber identifica que o mercado é uma construção humana, um espaço para interação e troca de mercadorias para satisfazer a necessidade do outro. No entanto, essas trocas são envolvidas por uma série de significados e regras a serem cumpridas, o que torna o mercado um espaço de relação social, dando a ele o papel de liga da sociedade.

Já Karl Polanyi (2011) se ocupa da autonomia do mercado e do domínio dele sobre a sociedade, diante da modernização das sociedades, possibilitando a maior circulação de mercadoria e a atomização das relações comerciais. No entanto, estas não são isoladas, mas sim enraizadas nas relações sociais. O momento em que o debate de Polanyi é realizado, temos uma racionalidade econômica dominante no pensamento social e o autor procura frisar que as relações econômicas e sociais são interdependes. Em contrapartida, para Mark Granovetter se trata de compreender que os enraizamentos das relações econômicas estão ligados às redes sociais que os sujeitos mantêm.

É adequado afirmar que o comércio justo deseja equidade nas relações 
comerciais entre "as maiores empresas mundiais e os trabalhadores economicamente mais pobres do mundo" (Redfern \& Snedker, 2002, p.4), o que coaduna com a concepção de Granovetteer (2007) sobre o mercado ser perpassado por relações humanas através de redes. Também identificamos a concepção de Polanyi (2011), no caso do processo de imersão, segundo a qual o mercado é gerido por agentes sociais, colocando em cheque a noção do sistema econômico como agente autorregulado e autônomo e abrindo espaço para pensarmos o mercado como um espaço do fazer social e com relações de interdependências entre as ações sociais, redes e agentes do mercado.

\section{Notas}

1. Artigo resultante da pesquisa de mestrado e do debate do artigo publicado no $38^{\circ}$ Encon tro da ANPOCS, 2014.

2. A relação Norte e Sul aqui se refere às concepções que trazem os países subdesenvolvidos e/ ou emergentes como parte do Sul e os países desenwvolvidos como parte do Norte, ou seja, considera-se as definições econômicas para concepção de Norte e Sul e não apenas a geográfica. 3. Organizações de mercados alternativos (tradução livre).

\section{Referências}

ABRAMOVAY, Ricardo. Entre Deus e o Diabo: mercados e interação humana nas ciências sociais. Tempo social. Revista de Sociologia da USP. São Paulo, v. 16, n. 2, pp. 35-64, nov. 2004.

ARISTÓTELES. Ética à Nicômaco. São Paulo: Nova Cultural, 1996.

BRAUDEL, Fernand. A dinâmica do capitalismo. Rio de Janeiro: Rocco, 1987.

CARVALHO, Antonio Daniel Alves. A Construção social do mercado fair trade no Brasil e no mundo. 2015. 115f. Dissertação (Mestrado em Sociologia), Instituto de Ciências Sociais, Universidade Federal de Alagoas, 2015.

FLO, WFTO. Carta de los principios del comercio justo. Disponível em: <http://www.fairtrade-advocacy.org/images/FTAO_charters_3rd_version _ES_v1.3.pdf $>$. Acessado em: 20 abr. 2014.

FLO. Aims of fairtrade standards. 2014. Disponível em: <http://www.fairtrade.net/aims-of-fairtrade-standards.html>. Acessado em: 10 jan 2014. 
. FLO. Disponível em: <http://www.fairtrade.net/ >. Acessado em: 10 dez. 2013.

GIDDENS, Anthony. As consequências da modernidade. São Paulo: Editora da Unesp, 1991.

GRANOVETTTER, Mark. Ação econômica e estrutura social: o problema da imersão. RAE Eletrônica, Fundação Getúlio Vargas, Rio de Janeiro, vol. 6, n. 1, pp. 1-41, jan./jun. 2007.

MACHADO, Nuno M. C. Karl Polanyi e a Nova Sociologia Económica: Notas sobre o conceito de (dis)embeddedness. Revista Crítica de Ciências Sociais, Coimbra, [Online], 2010. Disponível em: <http://rccs.revues.org/1771>. Acesso em: 04 Nov 2014.

POLANYI, Karl. A grande transformação. As origens de nossa época. Rio de Janeiro: Campus, 2011.

SCHNEIDER, Johann. Relatório da pesquisa mundial de comércio justo: parte 1. Brasília: SEBRAE, 2012.

SMELSER, Neil J.; SWEDBERG, Richard. Introducing Economic Sociology. In: (Eds.). The handbook of Economic Sociology. Princeton: Princeton University Press, 2005, p. 3-25.

SWEDBERG, Richard. Sociologia econômica: hoje e amanhã. Tempo Social, São Paulo, 16(2), 2004, pp. 7-34

WEBER, Max. Economia e Sociedade. Brasília: UnB, 1991.

REDFERN, A., \& SNEDKER, P. Creating market opportunities for small enterprises: Experiences of the fair trade movement. Genebra: ILO - SEED Working Paper no 30, 2002. 


\title{
The Fair Trade Market
}

\begin{abstract}
This paper develops social thinking about the market category and uses the sociological market concept to the fair trade market model. Fair trade is an alternative model to the conventional market and brings numerous elements to the questioning of the current international market model. Therefore, the goal of the article is to analyze the market as a sociological concept and to interpret the fair trade market model according to the conceptions made by the theoretical contributions of Weber, Polanyi and Granovetter. They collaborate with the economic sociology unfolding discussions about the market as a space of social action, so their works have been submitted to a bibliographic review. Considering the market as a result of social relations, this paper argues that the fair trade market considers the relationships among social actors to question the conventional international marking model and brings up another economical model that goes beyond the merely economical approach and considers social issues as well.
\end{abstract}

Keywords: Market; Economic sociology; Fair trade.

Recebido em 29 de abril de 2017.

Aceito em 21 de agosto de 2017. 